\title{
PROYECTO DE LEY ORGANICA DEL TRIBUNAL CONSTITUCIONAL
}

\author{
EXCMO. SR.:
}

En cumplimiento de un Acuerdo adoptado por el Consejo de Ministros, en su reunión del día 20 de abril de 1979, tengo el honor de remitir a V. E. Proyecto de Ley Orgánica del Tribunal Constitucional, al mismo tiempo que le manifiesto el interés de éste en que dicho Proyecto de Ley sea tramitado por el procedimiento de urgencia de acuerdo con lo dispuesto en los artículos 103 y siguientes del Reglamento Provisional del Congreso de los Diputados.

Dios guarde a V. E.

Madrid, 27 de abril de 1979

EL MINISTRO DE LA PRESIDENCIA

\section{EXCMO. SR. PRESIDENTE DEL CONGRESO DE LOS DIPUTADOS}

SUMARIO: Preámbulo.-Título $1 .^{\circ}$ Del Tribunal Constitucional.-Capítulo I. Del Tribunal Constitucional, su organización y funciones.-Capítulo II. De los Magistrados del Tribunal Constitucional.-Título 2. ${ }^{\circ}$ Del recurso de inconstitucionalidad.-Capítulo I. Del objeto del recurso de inconstitucionalidad.-Capítulo II. Del recurso de inconstitucionalidad promovido por vía principal o directa.-Capítulo III. Del recurso de inconstitucionalidad promovido por vía prejudicial.-Capítulo IV: De la sentencia en el recurso de insconstitucionalidad y de sus efectos.-Título 3. ${ }^{\circ}$ Del recurso de amparo constitucional.-Título 4. ${ }^{\circ}$ De los conflictos constitucionales de competencia y atribuciones.-Capítulo I. Clases de conflictos.-Capítulo II. De los conflictos constitucionales de competencia entre el Estado y las Comunidades Autónomas o de éstas entre sí.-Sección $1 .^{\text {a }}$ Conflictos de competencia positivos.-Sección 2. ${ }^{\text {a }}$ De los conflictos de competencia negativos.-Capítulo 111. De los conflictos de atribuciones entre órganos constitucionales del Estado.-Título $5 .^{\circ}$ Del procedimiento previsto en el artículo 161,2 de la Constitución.-Título $6 .^{\circ}$ Del control previo de inconstitucionalidad.-Capítulo I. Declaración sobre la constitucionalidad de los tratados internacionales.-Capítulo II. Recurso previo sobre la constitucionalidad de los textos que hayan de tramitarse como leyes orgánicas.-Título 7..$^{\circ}$ De las disposiciones comunes sobre procedimiento.-Título $8 .^{\circ}$ Del personal al servicio del Tribunal Constitucional.-Disposiciones transitorias.-Disposiciones adicionales. 


\section{PREAMBULO}

El Tribunal Constitucional, que debe asegurar la supremacía de la Constitución y garantizar la adecuación a ésta de todo nuestro ordenamiento, es, manifiestamente, una pieza esencial en la organización jurídico-política del Estado. Como es bien sabido, al recoger esta institución, nuestra Constitución sigue una corriente dominante en nuestro tiempo, mediante la que se persigue la progresiva juridificación de las relaciones políticas, para hacer cada vez más verdaderamente real el principio del imperio de la Ley.

La configuración de esta institución básica está confiada por la Constitución a una Ley orgánica, cuyas directrices fundamentales quedan establecidas ya muy suficientemente dentro del propio texto constitucional, del que la presente Ley es simple desarrollo.

En lo que toca a la composición del Tribunal, apenas hay adiciones dignas de ser mencionadas respecto de lo ya preceptuado por la Constitución. Para asegurar la independencia de los miembros del Tribunal Constitucional se ha establecido en la Ley el principio de la no reelegibilidad inmediata de los miembros del Tribunal Constitucional salvo para aquellos que, bien por haberse incorporado al mismo en el momento fundacional, bien por haber venido a sustituir vacantes producidas posteriormente por causas que no sean la de expiración del mandato de sus predecesores, han desempeñado el cargo por un tiempo inferior a los tres años. Igualmente y siguiendo algunas experiencias extranjeras, se ha precisado que el cese efectivo en las funciones de miembro del Tribunal se producirá sólo con la toma de posesión del sucesor, a fin de prevenir en lo posible situaciones de carencia a que ocasionalmente pudiera dar lugar el procedimiento constitucionalmente previsto para el nombramiento de los Magistrados.

En lo que toca también a la composición del Tribunal, la Ley ha establecido una división en Salas y abre la posibilidad de que tanto éstas como el propio Pleno actúen en Secciones para el despacho de aquellos asuntos que por sus características no requieran una deliberación extensa. Las dos Salas en que el Tribunal se divide han de asumir, en la economía de la Ley, el despacho de los recursos de amparo, sin perjuicio de la facultad que al Pleno del Tribunal se concede de avocarse al conocimiento de aquellos cuya importancia o trascendencia así lo aconsejen. Las Salas se configuran como Salas orgánicas, esto es, como Salas de composición permanente, a fin de garantizar al máximo la independencia de su actuación. Esta división de Salas, amén de otras razones, ha aconsejado la creación de la figura de Vicepresidente del Tribunal, que además de asumir 
la presidencia de la Sala $2 .^{\text {a }}$ pueda suplir al Presidente en casos de ausencia, de enfermedad o vacante.

El funcionamiento del Tribunal, en Pleno o en Salas, a través de Secciones de composición reducida debe hacer posible, como antes se dice, una decisión rápida en aquellos asuntos en que tal actuación sea posible, reduciendo así de manera significativa la carga de trabajo que verosímilmente ha de pesar sobre el Tribunal, sin mengua alguna para la garantía de los derechos que más bien debe resultar potenciada, en cuanto que con esta técnica se dota de una mayor eficacia a la actuación del Tribunal.

La regulación de las competencias específicas que los artículos 95 y 161 de la Constitución atribuyen al Tribunal no requiere tal vez aclaración alguna puesto que el Derecho Histórico y el Derecho Comparado ofrecen modelos de eficacia acreditada que basta con recoger. Las dos vías (directa e indirecta) para el recurso de inconstitucionalidad, la extensión del recurso de amparo a todas las vulneraciones de los derechos y libertades a que se refiere el apartado $2 .^{\circ} \mathrm{del}$ artículo 53 de la Constitución, la regulación de los conflictos de competencia, la impugnación por el Estado de los actos y resoluciones de las comunidades autónomas por causa de inconstitucionalidad y el examen previo de los tratados internacionales, se han desarrollado con estricto respeto de las normas constitucionales y sin otra finalidad que la de incrementar su eficacia real. El recurso de amparo, en particular, se ha ampliado considerablemente y para no privarlos desde el primer momento de la máxima exigencia se ha previsto que, en tanto que no se configura el procedimiento basado en los principios de preferencia y sumariedad a que se refiere el artículo 54 , apartado $2 .^{\circ}$ de la Constitución, pueda ser interpuesto en cuanto quede agotado el procedimiento especial que se configura en la Sección $2 .^{a}$ de la Ley de Protección Jurisdiccional de los Derechos Fundamentales.

Sólo dos competencias no mencionadas específicamente en la Constitución e introducidas al amparo de lo dispuesto en el párrafo d) del apartado $2 .^{\circ}$ del artículo 161 de la misma, viene a atribuir la presente Ley al Tribunal Constitucional: el conocimiento de los conflictos de atribuciones entre órganos constitucionales del Estado y el examen previo de las normas que hayan de ser promulgadas como leyes orgánicas.

La primera de estas competencias, de las que generalmente gozan los Tribunales Constitucionales existentes en otros Estados de nuestro mismo ámbito cultural, y cuya existencia se justifica en todo caso por esá aspiración de nuestro tiempo, a que antes se hace referencia, de juridificar al 
máximo todas las relaciones políticas, parece aún más necesaria en un Estado como el nuestro en el que la historia no ha permitido la consolidación de convenciones constitucionales que, en otros sistemas delimitan, más allá de la letra de la Constitución, las atribuciones concretas de cada uno de los órganos constitucionales y facilitan las rèlaciones entre ellos.

El frecuente recurso que la Constitución hace a la ley orgánica, el procedimiento especial que establece para la aprobación de las mismas e. incluso la protección de que éstas deben ser objeto en muchos casos por el Tribunal Constitucional, que forzadamente habrá de utilizar como parámetro de la constitucionalidad de otras normas, incorporándolas así de algún modo a lo que algún sector de la doctrina llama el bloque de la constitucionalidad, aconsejan abrir una vía previa destinada a asegurar su adecuación a la Constitución sin mengua alguna, como es obvio, de las facultades que corresponden a los órganos supremos del Estado y especialmente a las Cortes como representación del pueblo español.

El procedimiento ante el Tribunal se regula de manera congruente con las funciones de éste y con el resto de nuestro ordenamiento procesal al que dota de valor supletorio. Aunque esta fuerza supletoria de las normas procesales comunes baste muy probablemente para prevenir posibles lagunas, se dota además al Tribunal de facultades autoorganizativas para que pueda atender por sí mismo a la solución de aquellas cuestiones que las normas procedimentales por sí mismas no resuelvan.

Para llevar al máximo la independencia y la eficacia del Tribunal se le ha dotado, por último, de un total independencia presupuestaria y se le ha provisto de un cuerpo de letrados que ayuden a los Magistrados en el estudio de los asuntos.

\section{TITULO PRIMERO}

\section{Del Tribunal Constitucional}

\section{CAPITULO I}

Del Tribunal Constitucional, su organización y atribuciones

Artículo $10^{\circ}$

1. El Tribunal Constitucional, intérprete supremo de la Constitución, 
es independiente de los demás órganos constitucionales y está sometido sólo a la Constitución y a la presente Ley Orgánica.

2. Es único en su orden y extiende su jurisdicción a todo el territorio nacional.

Artículo 2.

1. El Tribunal Constitucional conocerá en los casos y en la forma que esta Ley determina:

a) Del recurso de inconstitucionalidad contra leyes, disposiciones normativas o actos con fuerza de ley.

b) Del recurso de amparo por violación de derechos y de libertades públicas susceptibles de esta protección.

c) De los conflictos constitucionales de competencia entre el Estado y las Comunidades Autónomas o de los de éstas entre sí.

d) De los conflictos de atribuciones entre los órganos constitucionales del Estado.

e) Del control previo de constitucionalidad en los casos previstos en la Constitución y en la presente Ley.

f) De las impugnaciones previstas en el número 2 del artículo 161 de la Constitución.

g) De la verificación de los nombramientos de los Magistrados del Tribunal Constitucional, para juzgar si los mismos reúnen los requisitos requeridos por la Constitución y la presente Ley.

2. El Tribunal Constitucional podrá dictar reglamentos sobre su propio funcionamiento y organización, así como sobre el régimen de su personal y servicios, dentro del ámbito de la presente Ley. Estos reglamentos, que deberán ser aprobados por el Tribunal en pleno, se publicarán en el Boletín Oficial del Estado, autorizados por su Presidente.

\section{Artículo 3. ${ }^{\circ}$}

La competencia del Tribunal Constitucional se extiende al conocimiento $\mathrm{y}$ decisión de las cuestiones prejudiciales e incidentales no pertenecientes al orden constitucional, directamente relacionadas con la materia de que conoce, pero a los solos efectos del enjuiciamiento constitucional de ésta.

\section{Artículo 4. ${ }^{\circ}$}

1. Ningún Juez o Tribunal, Autoridad o Poder Público, podrá promo- 
ver cuestión de jurisdicción o competencia al Tribunal Constitucional. 2. El Tribunal Constitucional apreciará, de oficio o a instancia de parte, su falta de jurisdicción o de competencia.

\section{Artículo 5.}

El Tribunal Constitucional está integrado por doce miembros, con el título de Magistrados del Tribunal Constitucional.

Artículo 6. ${ }^{\circ}$

1. El Tribunal Constitucional actúa en Pleno o en Sala.

2. El Pleno está integrado por todos los Magistrados del Tribunal. Lo preside el Presidente del Tribunal y, en su defecto, el Vicepresidente o el Magistrado más antiguo en el cargo y en caso de igual antigüedad el de mayor edad de entre éstos.

Artículo 7.

1. El Tribunal Constitucional consta de dos Salas. Cada Sala está compuesta por seis Magistrados nombrados por el Tribunal en Pleno.

2. La Sala Primera la preside el Presidente del Tribunal y, en su defecto, el Magistrado más antiguo, y caso de coincidir la antigüedad, el de más edad.

3. La Sala Segunda la preside el Vicepresidente del Tribunal y, en su defecto, el Magistrado más antiguo, y de coincidir la antigüedad, el de más edad de entre éstos.

Artículo 8. ${ }^{\circ}$

Para el despacho ordinario, la admisión o inadmisión de los recursos y los sobreseimientos, el Tribunal y las Salas actuarán en Secciones, compuestas por el respectivo Presidente o quien le sustituya, y dos Magistrados del Tribunal Constitucional.

Artículo 9.

1. El Tribunal elige de entre sus miembros por votación secreta a su Presidente y propone al Rey su nombramiento.

2. En primera votación se, requerirá la mayoría absoluta. Si ésta no se alcanzase se procederá a una segunda votación en la que resultará elegido quien obtuviese mayor número de votos. En caso de empate se efectuará 
una última votación y si éste se repitiese, será propuesto el de mayor antigüedad en el cargo y en caso de igualdad el de mayor edad.

3. El nombre del elegido se elevará al Rey para su nombramiento por un período de tres años, expirado el cual podrá ser reelegido.

\section{Artículo 10}

1. El Tribunal en pleno elegirá entre sus miembros por el procedimiento señalado en el artículo anterior y por el mismo período de tres años, un Vicepresidente; al que le incumbe sustituir al Presidente en caso de vacante, ausencia u otro motivo legal y presidir la Sala Segunda.

2. Cuando por cualquier causa legítima no pudieran el Presidente ni el Vicepresidente presidir el Tribunal, serán sustituidos por el Magistrado más antiguo, y en el supuesto de coincidir tal antigüedad, el que tenga mayor edad de entre éstos.

Artículo 11

El Tribunal en pleno conoce de los siguientes asuntos:

a) Del recurso de inconstitucionalidad contra Leyes y disposiciones normativas con fuerza de Ley.

b) Del recurso de amparo contra Leyes, disposiciones o actos con fuerza de Ley del Estado o de las Comunidades Autónomas.

c) De los conflictos constitucionales de atribuciones entre órganos del Estado.

d) De los conflictos de competencia entre el Estado y las Comunidades Autónomas o de éstas entre sí.

e) Del control previo de constitucionalidad.

f) De las impugnaciones previstas en el número 2 del artículo 161 de la Constitución.

g) De la recusación de los Magistrados del Tribunal Constitucional.

i) Del nombramiento de los Magistrados que han de integrar cada una de las Salas.

j) Del cese de los Magistrados del Tribunal Constitucional por incapacidad, incompatibilidad o por conducta contraria al ejercicio de la función judicial.

k) De la aprobación y modificación de los reglamentos del Tribunal.

1) De cualquier otro asunto que, siendo competencia del Tribunal, recabe para sí el Pleno, a propuesta del Presidente o de cinco Magistrados. 
Artículo 12

1. Las Salas del Tribunal Constitucional conocerán de los asuntos que, estando atribuidos a la justicia constitucional, no sean de la competencia del Pleno o de las Secciones.

2. También conocerán las Salas de aquellas cuestiones que, habiendo sido atribuidas al conocimiento de las Secciones, entiendan éstas o su Presidente que por su importancia o trascendencia deba resolver la Sala.

\section{Artículo 13}

La distribución de asuntos entre las Salas del Tribunal se efectuará según un turno establecido por el Pleno a propuesta de su Presidente.

\section{Artículo 14}

Cuando una Sala considere necesario apartarse en cualquier punto de la doctrina constitucional precedente sentada por el Tribunal, la cuestión se someterá a la decisión del Pleno.

\section{Artículo 15}

1. El Tribunal en Pleno puede adoptar acuerdos cuando estén presentes, al menos, ocho de sus miembros. Los acuerdos de las Salas requerirán la presencia de cuatro de sus miembros como mínimo.

2. Salvo los casos en que esta Ley establece otros requisitos las decisiones se adoptan por la mayoría de los miembros del Tribunal o de la Sala que participen en la deliberación, siendo de calidad el voto del Presidente.

\section{Artículo 16}

El Presidente del Tribunal Constitucional ostenta la representación del mismo; convoca y preside el Tribunal en Pleno y convoca las Salas cuando lo estime conveniente; adopta las medidas precisas para el funcionamiento del Tribunal, de las Salas y de las Secciones; comunica a las Cámaras, al Gobierno o al Consejo General del Poder Judicial, en cada caso, las vacantes; ejerce las potestades administrativas sobre el personal del Tribunal; insta del Ministerio de Justicia la convocatoria para cubrir las plazas de Secretarios, Oficiales, Auxiliares y Subalternos; ejerce todas las demás funciones no atribuidas al Pleno o a las Salas, y ocupa en el orden de precedencia la que la normativa específica señale. 


\section{CAPITULO II}

De los Magistrados del Tribunal Constitucional

\section{Artículo 17}

1. Los Magistrados del Tribunal Constitucional serán nombrados por el Rey, a propuesta de las Cámaras, del Gobierno y del Consejo General del Poder Judicial, en las condiciones que establece el articulo 159, I de la Constitución.

2. La designación para el cargo de Magistrado del Tribunal Constitucional se hará por nueve años, renovándose el Tribunal por terceras partes cada tres. Ningún Magistrado podrá ser propuesto al Rey para otro período inmediato salvo que hubiera ocupado el cargo por un plazo no superior a tres años.

\section{Artículo 18}

Antes de los cuatro meses previos a la fecha de expiración de los nombramientos, el Presidente del Tribunal solicitará de los Presidentes de los órganos que han de hacer las propuestas para la designación de los nuevos Magistrados, que inicien el procedimiento para ello.

2. Los Magistrados del Tribunal Constitucional continuarán en el ejercicio de sus funciones hasta que haya tomado posesión quien hubiere de sucederles.

3. Las vacantes producidas por causas distintas a la de la expiración del período para el que se hicieron los nombramientos, serán cubiertas con arreglo al mismo procedimiento utilizado para la designación del Magistrado que hubiere causado la vacante y por el tiempo que a éste restare.

\section{Artículo 19}

Los miembros del Tribunal Constitucional deberán ser nombrados entre Magistrados y Fiscales, profesores de Universidad, funcionarios públicos o abogados, todos ellos juristas de reconocida competencia con más de quince años de ejercicio profesional.

\section{Artículo 20}

1. Para ser Magistrado del Tribunal Constitucional se requiere además ser español y no hallarse comprendido en ninguna de las causas de incapacidad o incompatibilidad previstos para los miembros del Poder Judicial. 
2. Cuando alguien en quien concurriere causa de incompatibilidad fuere propuesto como Magistrado del Tribunal deberá, antes de posesionarse, cesar en el cargo o en la actividad incompatible. Si no lo hiciere en el plazo de diez días siguientes a la propuesta, se entenderá que renuncia al cargo de Magistrado del Tribunal Constitucional.

\section{Artículo 21}

El cargo de Magistrado del Tribunal Constitucional es incompatible: $\left.1 .^{\circ}\right)$ Con el de Diputado y Senador; $2 .^{\circ}$ ) Con cualquier cargo político o administrativo del Estado, las Comunidades Autónomas, las provincias u otras entidades locales; $3 .^{\circ}$ ) Con el ejercicio de cualquiera otra jurisdicción o de cualquier actividad propia de la carrera judicial o fiscal; $4 .^{\circ}$ ) Con empleos de todas clases en los Tribunales y Juzgados de cualquier orden jurisdiccional; $5^{\circ}$ ) Con el desempeño de funciones directivas en los partidos políticos, sindicatos, asociaciones empresariales y colegios profesionales, y con cualquier clase de empleo al servicio de los mismos; $6 . .^{\circ}$ ) Con el desempeño de otra actividad profesional, pública o privada; $7 .^{\circ}$ ) Con toda actividad mercantil.

\section{Artículo 22}

Los miembros de la Carrera Judicial y Fiscal, y en general, los funcionarios públicos nombrados Magistrados del Tribunal, pasarán a la situación de excedencia especial en su carrera de origen.

\section{Artículo 23}

El Presidente, el Vicepresidente y los demás Magistrados del Tribunal Constitucional prestan al asumir su cargo ante el Rey, el siguiente juramento o promesa:

«Juro (o prometo) lealtad al Rey, así como guardar y hacer guardar fielmente y en todo tiempo, la Constitución Española y cumplir mis deberes como Magistrado Constitucional.»

\section{Artículo 24}

Los Magistrados del Tribunal Constitucional son inamovibles, y no podrán ser destituidos, suspendidos o jubilados, sino por alguna de las causas que esta Ley establece. 
Artículo 25

Los Magistrados del Tribunal Constitucional cesan por alguna de las causas siguientes: $1 .^{\circ}$ ) Por renuncia, aceptada por el Presidente del Tribunal; $2^{\circ}$ ) Por expiración del plazo de su nombramiento o por cumplimiento de la edad de setenta años, aunque la edad de jubilación en el Cuerpo o profesión de origen sea distinta; $3 .^{\circ}$ ) Por incurrir en alguna causa de incapacidad; $4^{\circ}$ ) Por haber incurrido en alguna de las incompatibilidades previstas en esta Ley; $5 .^{\circ}$ ) Por haber sido declarado responsable civilmente, por dolo o culpa grave; $6 .^{\circ}$ ) Por haber sido condenado por delito doloso o por culpa grave, cualquiera que sea la pena; $7 .^{\circ}$ ) Por dejar de atender con diligencia y sin causa justificada a los deberes del cargo; $8 .^{\circ}$ ) Por llevar, dentro o fuera del ejercicio de la función jurisdiccional constitucional, una conducta contraria a los principios de imparcialidad política, que deben inspirar su cargo cuando viole la reserva que impone éste; 9. ${ }^{\circ}$ ) Por incurrir en otras actuaciones contrarias a la dignidad de la función judicial.

2. El cese en el cargo de Magistrado del Tribunal Constitucional, en los casos $1 .^{\circ}, 2 .^{\circ}, 5 .^{\circ}$ y $6 .^{\circ}$, se decretará por el Presidente; en los demás supuestos decidirá el Tribunal en Pleno; por mayoría simple en los casos $3 .^{\circ}$ y $4 .^{\circ}$, y por mayoría de las tres cuartas partes de sus miembros en los casos $7 .^{\circ}, 8 .^{\circ}$ y $9 .^{\circ}$.

Artículo 26

Los Magistrados del Tribunal Constitucional podrán ser suspendidos por el Tribunal en Pleno, como medida previa en caso de procesamiento o por el tiempo indispensable para resolver sobre la concurrencia de alguna de las causas de cese establecidas en el artículo anterior. La suspensión requiere el voto favorable de las tres cuartas partes de los miembros del Tribunal.

\section{Artículo 27}

1. Cuando el Magistrado del Tribunal proceda de cualquier Cuerpo de funcionarios con derecho a jubilación, se le computará, a los efectos de determinación del haber pasivo, el tiempo de desempeño de las funciones constitucionales y se calculará aquél sobre el total de las remuneraciones que hayan correspondido al Magistrado del Tribunal Constitucional durante el último año.

2. Los Magistrados del Tribunal que hubieren desempeñado el cargo durante un mínimo de tres años, tendrán derecho a una remuneración de 
transición por un año, en la cuantía de sus remuneraciones como Magistrados del Tribunal Constitucional.

\section{Artículo 28}

Los Magistrados del Tribunal Constitucional no pueden ser perseguidos por las opiniones expresadas y los votos emitidos en el ejercicio de sus funciones, sino en los casos y con los requisitos establecidos para los miembros del poder judicial.

\section{Artículo 29}

La competencia para procesar, enjuiciar y exigir la responsabilidad penal de los Magistrados del Tribunal Constitucional queda reservada a la Sala de lo Penal del Tribunal Supremo.

\section{TITULO SEGUNDO}

\section{Del recurso de inconstitucionalidad}

\section{CAPITULO I}

Del objeto del recurso de inconstitucionalidad

Artículo 30

Son susceptibles del recurso de inconstitucionalidad:

a) Los Estatutos de autonomía y las demás leyes orgánicas.

b) Las demás Leyes del Estado en cualquiera de sus formas y los actos y disposiciones normativas del Estado con fuerza de Ley; en el caso de los Decretos Legislativos, la competencia del Tribunal se entiende sin perjuicio de la que corresponda a los Tribunales ordinarios para controlar los eventuales excesos en el desarrollo de la delegación legislativa de que tomen causa.

c) Los Tratados Internacionales, sea cual sea la forma que revista la presentación de consentimiento.

d) Los Reglamentos de las Cámaras y de las Cortes Generales.

e) Las Leyes, actos y disposiciones normativas con fuerza de Ley de 
las Comunidades Autónomas, con la misma salvedad formulada en el apartado b) respecto a los casos de delegación legislativa.

f) Los Reglamentos de las Asambleas legislativas de las Comunidades Autónomas.

Artículo 31

1. Mediante el recurso de inconstitucionalidad, el Tribunal garantiza la primacía de la Constitución y enjuicia la conformidad o disconformidad con ella de las Leyes, disposiciones o actos impugnados.

2. Para apreciar la conformidad o disconformidad con la Constitución de una Ley, disposición o acto con fuerza de Ley del Estado o de las Comunidades Autónomas, habrán de tenerse en cuenta, en su caso, además de los propios preceptos constitucionales, las normas que, dentro del marco constitucional, se hubiesen dictado para delimitar el ámbito competencial del Estado y las diferentes Comunidades Autónomas, o regular o armonizar el ejercicio de estas competencias concretas.

\section{Artículo 32}

El recurso de inconstitucionalidad podrá promoverse, bien por la vía principal o directa, bien por la vía incidental, en un proceso abierto de cualquier clase en que la constitucionalidad de la norma a aplicar para la decisión del mismo se presente como cuestión prejudicial.

La desestimación de un recurso de inconstitucionalidad contra una Ley, disposición o acto con fuerza de Ley promovido en vía principal, no será obstáculo para que la misma Ley, disposición o acto puedan ser impugnadas en vía incidental con ocasión de su aplicación en otro proceso.

\section{Artículo 33}

El recurso de inconstitucionalidad, bien se suscite en vía principal, bien como cuestión prejudicial de un proceso en curso, no suspenderá la vigencia y aplicabilidad de la Ley, disposición o actos impugnados excepto en el caso de que el Gobierno se ampare en lo dispuesto en el número 2 del artículo 161 de la Constitución para impugnar disposiciones de las Comunidades Autónomas que tengan fuerza de Ley. 


\section{CAPITULO II}

Del recurso de inconstitucionalidad promovido por vía principal o directa Artículo 34

El recurso de inconstitucionalidad contra cualquiera de las Leyes, disposiciones o actos con fuerza de Ley podrá promoverse una vez dichas Leyes, disposiciones o actos se hayan publicado oficialmente, con independencia de su aplicación.

\section{Artículo 35}

1. Para el ejercicio del recurso general de inconstitucionalidad contra disposiciones o resoluciones de las Comunidades Autónomas, cuando se utilice este cauce procesal y dichas disposiciones tengan fuerza de Ley, está legitimado únicamente el Gobierno, de acuerdo con el artículo 161, 2 de la Constitución.

2. Para el ejercicio del recurso de inconstitucionalidad en vía principal o directa contra Leyes, disposiciones o actos con fuerza de Ley, están legitimados:

1. $\quad$ El Presidente del Gobierno.

2. El Defensor del Pueblo.

3. Cincuenta Diputados.

4. ${ }^{\circ}$ Cincuenta Senadores.

3. Están también legitimados para el ejercicio del recurso de inconstitucionalidad en vía principal contra las Leyes, disposiciones o actos con fuerza de Ley que puedan afectar a su ámbito propio de autonomía:

1. Los órganos colegiados ejecutivos de las Comunidades Autónomas, por acuerdos válidamente adoptados por los mismos.

2. Las Asambleas de las Comunidades Autónomas, previo acuerdo especial al efecto.

4. Los órganos colegiados ejecutivos de las Comunidades Autónomas están legitimados, en todo caso, para impugnar las Leyes, actos y disposiciones con fuerza de Ley emanados de las respectivas Asambleas legislativas.

Artículo 36

El recurso de inconstitucionalidad en vía principal o directa se formulará dentro del plazo de tres meses a partir de la publicación de la Ley, 
disposición o acto impugnado, mediante demanda presentada ante el Tribunal Constitucional, en la que deberán expresarse las circunstancias de identidad de las personas u órganos que ejercitan la acción y, en su caso, de sus comisionados, concretar la Ley, disposición o àcto impugnado, en todo o en parte, y precisar el precepto constitucional que se entiende infringido.

\section{Artículo 37}

Presentada la demanda y abierto el proceso, si es que reuniera los requisitos formales, el Tribunal dará traslado de la misma al Congreso de los Diputados o al Senado por conducto de sus Presidentes, al Gobierno, por conducto del Ministro de Justicia y a los órganos correspondientes de la Comunidad Autónoma, si procediese, a fin de que puedan comparecer en el recurso de inconstitucionalidad para defender la Ley o adherirse a la demanda de inconstitucionalidad mediante las alegaciones que estimen oportunas.

La personación y formulación de alegaciones deberá hacerse en el plazo de quince días, transcurrido el cual se dictará sentencia en el de diez, salvo que el Tribunal, para mayor información, estime necesario un plazo más amplio, que no podrá exceder de treinta días.

\section{CAPITULO III}

Del recurso de inconstitucionalidad promovido por vía prejudicial

\section{Artículo 38}

1. Cuando un Juez o Tribunal considere que una norma con rango de Ley aplicable al caso y de cuya validez dependa el fallo pueda ser contraria a la Constitución, planteará la cuestión al Tribunal Constitucional con sujeción a lo dispuesto en esta Ley.

2. El órgano judicial sólo podrá plantear la cuestión una vez concluso el procedimiento y dentro del plazo para dictar sentencia, debiendo concretar la Ley o norma con fuerza de Ley cuya constitucionalidad se cuestiona, el precepto constitucional que se supone infringido y especificar y justificar en qué medida la decisión del proceso depende de la validez de la norma en cuestión. La cuestión se planteará mediante Auto del que se dará 
cuenta a las partes y al Ministerio fiscal para que en el plazo improrrogable de diez dias hagan las alegaciones que estimen pertinentes.

Dicho Auto no será apelable o susceptible de recurso de ninguna clase.

\section{Artículo 39}

Transcurrido el plazo fijado en el artículo anterior el órgano judicial elevará al Tribunal Constitucional el Auto que acuerde plantear la cuestión prejudicial de inconstitucionalidad de la Ley, disposición o acto con fuerza de Ley que ha de ser aplicable para la decisión del proceso, junto con una copia de los autos principales y de las alegaciones previstas en el artículo anterior, si las hubiere.

\section{Artículo 40}

1. Recibidas en el Tribunal Constitucional las actuaciones, la inconstitucionalidad se sustanciará por los trámites del apartado segundo de este artículo. No obstante, podrá el Tribunal rechazar, en trámite de admisión, mediante Auto y sin otra audiencia que la del Fiscal General del Estado, el incidente de prejudicialidad cuando faltaren las condiciones procesales o fuere notoriamente infundada la cuestión suscitada. Esta decisión será motivada.

2. El Tribunal Constitucional dará traslado de la cuestión al Fiscal General del Estado, al Gobierno, por conducto del Ministerio de Justicia y, en caso de impugnarse una Ley, disposición o acto con fuerza de Ley dictada por una Comunidad Autónoma, ál órgano ejecutivo de la misma, todos los cuales podrán formular alegaciones sobre la cuestión planteada en plazo común improrrogable de quince días. Concluido éste, el Tribunal dictará sentencia en el plazo de quince días.

\section{Artículo 41}

Si transcurriesen sesenta días desde que se elevó el Auto planteando la cuestión, sin que el Tribunal Constitucional hubiera dictado sentencia o sobreseimiento o declarado inadmisible el recurso, o prorrogado mediante Auto y por tiempo determinado el plazo de que dispone el órgano judicial que elevó la consulta para dictar sentencia se entenderá que el Tribunal no ha encontrado motivos de inconstitucionalidad y el órgano judicial estimará la cuestión como no planteada, debiendo dictar sentencia con arreglo a la legislación vigente. 


\section{CAPITULO IV}

De la sentencia del recurso de inconstitucionalidad y de-sus efectos

\section{Artículo 42}

1. Las sentencias recaídas en recursos de inconstitucionalidad, producirán efectos, una vez notificadas a las partes. Vincularán a todos los órganos del Estado y, en particular, cuando se trate de sentencias recaídas en recursos promovidos por vía incidental dentro de otros procesos, al órgano judicial competente para la decisión de éste.

2. Las sentencias que declaren la inconstitucionalidad de una Ley, disposición o acto con fuerza de Ley producirán efectos generales desde la fecha de su publicación en el Boletín Oficial del Estado. Las sentencias desestimatorias dictadas en recurso de inconstitucionalidad promovido por vía principal impedirán cualquier planteamiento ulterior de cuestión en la misma vía.

\section{Artículo 43}

1. Cuando la sentencia declare la inconstitucionalidad de la Ley, disposición o acto con fuerza de Ley, declarará simultáneamente la nulidad de los mismos, concretando los preceptos, en particular a los que ha de extenderse esta nulidad por razón de consecuencia o conexión directa con los impugnados. Subsistirá la validez de la Ley, disposición o acto enjuiciados en la parte no afectada por la declaración de inconstitucionalidad.

2. La declaración de inconstitucionalidad podrá basarla el Tribunal Constitucional en la violación de otra norma de la Constitución distinta a la invocada por los recurrentes.

\section{Artículo 44}

1. Las sentencias declaratorias de la inconstitucionalidad de Leyes, disposiciones o actos con fuerza de Ley no permitirán reabrir procesos fenecidos mediante sentencia con fuerza de cosa juzgada en los que se haya hecho aplicación de las Leyes, disposiciones o actos inconstitucionales, salvo en el caso de los procesos penales en que, como consecuencia de la nulidad de la norma aplicada, resulte una reducción de la pena o una exclusión o limitación de la responsabilidad.

2. En todo caso, la jurisprudencia recaída sobre Leyes, disposiciones 
o actos enjuiciados por el Tribunal Constitucional habrá de entenderse corregida por la doctrina derivada de las sentencias y Autos que resuelvan los recursos de inconstitucionalidad.

\section{TITULO TERCERO}

\section{Del recurso de amparo constitucional}

Artículo 45

1. Los derechos y libertades reconocidos en los artículos 14 a 29 de la Constitución serán susceptibles de amparo constitucional, en los casos y formas que esta Ley establece, sin perjuicio de su tutela general encomendada a los Tribunales de Justicia.

Igual protección será aplicable a la objeción de conciencia reconocida en el artículo 30 de la Constitución.

2. El recurso de amparo constitucional protege a todos los ciudadanos, en los términos de esta Ley, frente a cualquier acto de los poderes públicos del Estado, las Comunidades Autónomas o de otros entes públicos de carácter territorial, institucional o corporativo, que desconozca o vulnere los derechos y libertades a que se refiere el apartado anterior.

3. En el amparo constitucional no pueden hacerse valer otras pretensiones que las dirigidas a restablecer o preservar los derechos o libertades por razón de las cuales se formuló el recurso.

\section{Artículo 46}

1. Cuando por Ley, o por disposición o acto con valor de Ley formal, del Estado o de las Comunidades Autónomas, que hubieren de ser cumplidos directamente sin previo requerimiento o acto de sujeción individual, se violen o pongan en peligro actual o inmediato los derechos y libertades susceptibles de amparo constitucional, la persona directamente afectada, así como el Defensor del Pueblo y el Ministerio Fiscal, podrá interponer recurso de amparo ante el Tribunal Constitucional.

El recurso de amparo deberá interponerse en el plazo de tres meses, a contar desde el día siguiente a la publicación de la Ley, o acto o disposición con valor de Ley formal. La falta de impugnación directa no será obstáculo, sin embargo, para recabar posteriormente el amparo constitucional frente a actos del Poder Público, fundados en la norma que se repute inconstitucional. 
2. Las demás decisiones o actos sin valor de Ley emanados de las Cortes o de cualquiera de sus órganos, o de las Asambleas legislativas de la Comunidades Autónomas o de sus órganos que violen los derechos y libertades susceptibles de amparo constitucional podrán ser también recurridos dentro del mismo plazo de tres meses desde que, con arreglo a las normas internas de las Cámaras o Asambleas, fuesen firmes.

\section{Artículo 47}

1. Las violaciones de los derechos y libertades antes referidos originadas por disposiciones, actos jurídicos o simple vía de hecho del Gobierno o de sus autoridades o funcionarios, o de los órganos ejecutivos colegiados de las Comunidades Autónomas o de sus autoridades o funcionarios o provenientes de cualesquiera otros entes públicos o sus funcionarios o agentes, podrán dar lugar al recurso de amparo una vez que se haya agotado la vía judicial procedente, de acuerdo con el artículo 53 de la Constitución.

2. El plazo para interponer el recurso de amparo constitucional será el de los veinte días siguientes a la notificación de la resolución recaída en el previo proceso judicial.

3. El recurso sólo podrá fundarse en la infracción o errónea interpretación, producida en la decisión final de la vía judicial agotada, de los preceptos constitucionales que reconocen los derechos o libertades susceptibles de amparo.

Artículo 48

1. Las violaciones de los derechos y libertades susceptibles de amparo constitucional que tuvieran su origen inmediato y directo en un acto $u$ omisión de un órgano judicial podrán dar lugar a este recurso siempre que se cumplan los requisitos siguientes:

a) Que se hayan agotado todos los recursos utilizables dentro de la vía judicial.

b) Que la violación del derecho o libertad sea imputable de modo inmediato y directo a una acción u omisión del órgano judicial con independencia de los hechos que dieron lugar al proceso en que aquéllas se produjeron acerca de los que, en ningún caso, entrará a conocer el Tribunal Constitucional.

c) Que se hubiese hecho invocación formal dentro del proceso judicial correspondiente del derecho constitucional vulnerado, tan pronto como, una vez conocida la violación, hubiera lugar para ello. 
2. El plazo para interponer el recurso de amparo será de veinte días a partir de la notificación de la resolución recaída en el previo proceso judicial.

\section{Artículo 49}

1. La solicitud de amparo constitucional contra las violaciones del derecho a la objeción de conciencia sólo podrá presentarse una vez que sea ejecutoria la decisión que impone la obligación de prestar el servicio militar.

2. El plazo para interponer el recurso de amparo será de veinte días a partir de la notificación de la resolución recaída.

\section{Artículo 50}

1. Podrán interponer el recurso de amparo constitucional en los casos de los artículos 49 y 50 , quienes hayan sido parte en el proceso judicial previo correspondiente.

2. También podrán promover el recurso el Defensor de Pueblo y el Ministerio Fiscal. En estos casos, la Sala competente para conocer del amparo constitucional lo comunicará a los posibles agraviados que fueran conocidos y ordenará anunciar la interposición del recursos en el Boletín Oficial del Estado a efectos de comparecencia de otros posibles interesados.

\section{Artículo 51}

1. Podrán comparecer en el proceso de amparo constitucional adoptando la posición de demandado o coadyuvante las personas favorecidas por la disposición, acto o hecho en razón del cual se formule el recurso o que ostenten un interés legítimo en el mismo.

2. El Ministerio Fiscal intervendrá en todos los procesos de amparo, en defensa de la legalidad, de los derechos de los ciudadanos y del interés público tutelado por la Ley.

\section{Artículo 52}

El conocimiento de los recursos de amparo constitucional corresponde a las Salas del Tribunal Constitucional.

No obstante el recurso de amparo constitucional frente a Ley, disposición o acto con fuerza de Ley, será conocido por el Tribunal en Pleno y se tramitará a partir de la admisión de la demanda como recurso de inconsti- 
tucionalidad, sin perjuicio de las especialidades derivadas de la intervención en él de las personas legitimadas.

\section{Artículo 53}

1. El recurso de amparo constitucional se iniciará por demanda, en la que se expondrán con claridad y concisión los hechos que la fundamenten, se citarán los preceptos constitucionales que se estimen infringidos y se fijará con precisión el amparo que se solicita para preservar o restablecer el derecho o libertad que se considere vulnerado.

2. Con la demanda se acompañarán:

a) El documento que acredite la representación del solicitante del amparo.

b) La copia, traslado o certificación de la resolución recaída en el previo procedimiento administrativo o judicial.

Cuando se trate de amparo constitucional frente a Ley se citará la Ley, y precepto, que se estima viola el derecho o libertad fundamental.

3. A la demanda se acompañarán también tantas copias literales de la misma y de los documentos presentados como partes en el previo proceso si le hubiere y una más para el Ministerio Fiscal.

\section{Artículo 54}

1. La Sala, previa audiencia del solicitante de amparo y del Ministerio Fiscal por plazo común que no excederá de diez días, podrá acordar motivadamente la inadmisión cuando se den algunos de los supuestos siguientes:

a) Cuando la demanda hubiese sido presentada fuera de plazo.

b) Cuando la demanda presentada sea defectuosa por carecer de los requisitos legales o no ir acompañada de los documentos preceptivos, siempre que los defectos no se subsanen en el plazo mismo de la audiencia.

2. También podrá dictarse el sobreseimiento previo, con idénticos requisitos:

a) Cuando la demanda se deduzca respecto de derechos o libertades no susceptibles de amparo constitucional.

b) Cuando la demanda carezca, manifiestamente, de contenido que justifique una decisión por parte del Tribunal Constitucional.

c) Cuando el Tribunal Constitucional, haya resuelto en el fondo un recurso de inconstitucionalidad o un recurso de amparo en supuesto que guarde igualdad jurídica esencial, y se hubiera rechazado. 
d) Cuando la demanda de amparo se deduzca respecto de situaciones consumadas, haciendo imposible el otorgamiento de la protección constitucional, sin perjuicio de la eventual indemnización en la vía procesal pertinente.

3. Contra el acuerdo de inadmisión o de sobreseimiento previo de una demanda de amparo constitucional no cabrá recurso alguno.

\section{Artículo 55}

1. Cuando se admita la demanda de amparo la Sala requerirá por vía telegráfica y con carácter urgente al Juez, Tribunal o Autoridad que conoció del procedimiento previo para que en el plazo, que no podrá exceder de diez días, remita las actuaciones o testimonio de ellas.

2. El Juez, Tribunal o Autoridad, acusarán recibo por vía telegráfica del requerimiento, cumplimentarán el envío dentro del plazo señalado y emplazarán a quienes fueron parte en el previo procedimiento, para que puedan comparecer en el proceso de amparo constitucional en el plazo de diez días.

\section{Artículo 56}

Recibidas las actuaciones y transcurrido el tiempo de emplazamiento, la Sala dará vista de las mismas, en la sede del Tribunal, al que promovió el amparo, a los personados en el proceso, al Abogado del Estado, si estuviera interesada la Administración Pública, y al Ministerio Fiscal. La vista será por plazo común que no podrá exceder de veinte días y durante él podrán presentarse las alegaciones procedentes.

Presentadas las alegaciones o transcurrido el plazo otorgado, sin otros trámites, la Sala pronunciará la Sentencia que proceda, en el plazo de diez días.

\section{Artículo 57}

La Sala, al conocer del fondo del asunto pronunciará en su sentencia alguno de estos fallos:

a) Sobreseimiento del recurso.

b) Otorgamiento de amparo.

c) Desestimación del amparo sin perjuicio, en su caso, del ejercicio de las vías judiciales por los interesados. 
1. Cuando la Sala conozca del recurso de amparo respecto de decisiones de los Jueces y Tribunales, se abstendrá de cualquier revisión, fiscalización o censura de los aspectos jurisdiccionales de las mismas, tanto en lo referente al acierto de la fijación de los hechos, como en el de la interpretación y aplicación del derecho al caso concreto.

2. La Sala limitará su función a concretar si se han violado derechos o libertades del demandante, y a restablecer estos derechos o libertades.

\section{Artículo 59}

El sobreseimiento procederá en aquellos casos que hubieran justificado el sobreseimiento previo y, además, en todos aquellos en que, por acto o hecho, o por resolución o disposición posterior, o por cualquier otra causa, el amparo solicitado resulte innecesario.

\section{Artículo 61}

La Sentencia que otorgare el amparo contendrá alguno o algunos de los proncunciamientos siguientes:

a) Anulación o declaración de nulidad de la disposición, acto o resolución que hayan impedido el pleno ejercicio de los derechos o libertades protegidos, con determinación, en su caso, de la extensión de sus efectos.

b) Reconocimiento del derecho o libertad pública, de conformidad con su contenido constitucionalmente declarado.

c) Restablecimiento del recurrente en la integridad de su derecho o libertad con la adopción, en su caso, de las medidas apropiadas para su preservación.

\section{Artículo 61}

1. La Sala competente para conocer del recurso de amparo suspenderá, a instancia del agraviado, del Defensor del Pueblo o del Ministerio Fiscal, la ejecución de la Ley, de la disposición o acto con valor de Ley formal, o del acto del Poder público, por razón del cual se reclame la protección constitucional, cuando la ejecución hubiese de ocasionar un perjuicio que haría perder al amparo su finalidad. Podrá, no obstante, la Sala denegar la suspensión cuando de ésta pueda seguirse perturbación grave de los intereses generales, o de los derechos fundamentales o libertades públicas de un tercero. 
2. La suspensión podrá pedirse en cualquier tiempo, antes de haberse pronunciado sentencia o decidirse el amparo de otro modo. El incidente de suspensión se sustanciará con audiencia de las partes, y del Ministerio Fiscal, por plazo común que no excederá de tres días, y previo informe a las autoridades responsables, si la Sala lo creyera necesario.

La suspensión podrá acordarse con o sin afianzamiento. La Sala podrá condicionar la denegación de la suspensión en el caso de que pudiera seguirse perturbación grave de los derechos de un tercero, a la constitución de caución suficiente para responder de los daños o perjuicios que pudieran originarse.

\section{Artículo 62}

La suspensión, o la denegación de la suspensión, puede ser modificada durante el curso del juicio de amparo constitucional, de oficio o a instancia de parte, cuando sobrevinieren circunstancias que no pudieron ser conocidas cuando se conoció del incidente de suspensión.

Artículo 63

Será competente para resolver sobre las peticiones de indemnización de los daños causados como consecuencia de la concesión o denegación de la suspensión el Juez ordinario, a cuya disposición se pondrán las fianzas constituidas.

Las peticiones de indemnización, que se sustanciarán por el trámite de los incidentes, deberán presentarse dentro del plazo de un año de publicación de la sentencia del Tribunal Constitucional.

\section{TITULO CUARTO}

De los conflictos constitucionales de competencia y de atribuciones

\section{CAPITULO I}

\section{Clases de conflictos}

\section{Artículo 64}

El Tribunal Constitucional entenderá de los conflictos que se susciten 
sobre las competencias o atribuciones asignadas directamente por la Constitución, los Estatutos de Autonomía o las leyes orgánicas u ordinarias dictadas para delimitar los ámbitos propios del Estado y las Comunidades Autónomas y que opongan:

1. ${ }^{\circ}$ Al Estado con una o más Comunidades Autónomas.

2..$^{\circ}$ A dos o más Comunidades Autónomas entre sí.

3. ${ }^{\circ}$ Al Gobierno, con el Congreso de los Diputados, el Senado, el Tribunal de Cuentas, el Consejo General del Poder Judicial o a cualesquiera de estos órganos entre sí.

\section{CAPITULO II}

De los conflictos constitucionales de competencia entre el Estado y las Comunidades Autónomas o de éstas entre sí

\section{Artículo 65}

Los conflictos de competencia que opongan al Estado con una Comunidad Autónoma o a éstas entre sí podrán ser suscitados por el Gobierno o por los órganos colegiados ejecutivos de las Comunidades Autónomas, en la forma que determinan los artículos siguientes. Los conflictos negativos podrán ser instados también por las personas físicas o jurídicas o por los particulares interesados.

\section{Artículo 66}

1. Pueden dar lugar al planteamiento de los conflictos de competencia las disposiciones, resoluciones y actos emanados de los órganos del Estado o de los órganos de las Comunidades Autónomas o la omisión de tales disposiciones, resoluciones o actos.

2. Cuando se plantease un conflicto de los mencionados en el artículo anterior con motivo de una disposición, resolución o acto cuya impugnación estuviese pendiente ante cualquier Tribunal, éste suspenderá el curso del proceso hasta la decisión del conflicto constitucional.

3. La decisión del Tribunal Constitucional será vinculante para todos en la materia en ella resuelta. 


\section{SECCION $1 .^{\mathrm{a}}$}

Conflictos de competencia positivos

\section{Artículo 67}

Cuando el Gobierno considere que una disposición o resolución de una Comunidad Autónoma no respeta el orden de competencia establecido en la Constitución, en los Estatutos de Autonomía o en las Leyes Orgánicas correspondientes podrá formalizar directamente ante el Tribunal Constitucional, en el plazo de dos meses, el conflicto de competencia al amparo de lo dispuesto en el artículo 161.2 de la Constitución, y con los efectos en él previstos.

\section{Artículo 68}

1. Cuando el órgano ejecutivo superior de una Comunidad Autónoma considerase que una disposición, resolución o cualquier otro acto emanado de la autoridad de otra Comunidad Autónoma o del Estado no respeta el orden de competencias establecido en la Constitución, en los Estatutos de Autonomía o en las leyes orgánicas correspondientes, requerirán a aquélla o a éste para que sea derogada la disposición o anulada la resolución o el acto en cuestión.

2. El requerimiento de incompetencia podrá formularse dentro de los dos meses siguientes al día de la publicación o comunicación de la norma, resolución $o$ acto que se entiendan viciados de incompetencia o con motivo de un acto concreto de aplicación y se dirigirá directamente al Gobierno o al órgano ejecutivo superior de la otra Comunidad Autónoma dando cuenta igualmente al Gobierno en este caso.

3. En el requerimiento se especificarán con claridad los preceptos de la disposición o los puntos concretos de la resolución o acto viciados de incompetencia así como las disposiciones legales o constitucionales de las que el vicio resulte.

4. El órgano requerido, si estima fundado el requerimiento, deberá atenderlo en el plazo máximo de un mes a partir de su recepción, comunicándolo así al requiriente y al Gobierno, si éste no actuara en tal condición. Si no lo estimara fundado deberá igualmente rechazarlo dentro del mismo plazo, a cuyo término se entenderán en todo caso rechazados los requerimientos no atendidos.

5. Dentro del mes siguiente a la notificación del rechazo o al término 
del plazo a que se refiere el apartado anterior, el órgano requirente si no ha obtenido satisfacción, podrá plantear el conflicto ante el Tribunal Constitucional, certificando el cumplimiento infructuoso del trámite de requerimiento y alegando los fundamentos jurídicos en que éste se apoya.

\section{Artículo 69}

1. En el término de diez días, el Tribunal comunicará al Gobierno u órgano autonómico correspondientes la iniciación del conflicto, señalándose plazo, que en ningún caso será mayor de veinte días, para que aporte cuantos documentos y alegaciones considere convenientes.

2. De acuerdo con lo previsto en el artículo 161,2 de la Constitución, cuando el conflicto hubiere sido entablado por el Gobierno, su formalización comunicada por el Tribunal suspenderá inmediatamente la vigencia de la disposición, resolución o acto que hubiesen dado origen al conflicto.

3. Cuando lo entablare una Comunidad Autónoma, ésta podrá solicitar del Tribunal la suspensión de la disposición, resolución o acto objeto del conflicto, invocando perjuicios de imposible o difícil reparación, el Tribunal acordará o denegará libremente la suspensión solicitada.

4. El planteamiento del conflicto iniciado por el Gobierno y, en su caso, el Auto del Tribunal por el que se acuerde la suspensión de la disposición, resolución o acto objeto del conflicto serán notificados a los interesados y publicados en el correspondiente Diario Oficial por el propio Tribunal.

\section{Artículo 70}

1. El Tribunal podrá solicitar de las partes cuantas informaciones, aclaraciones o precisiones juzgue necesarias para su decisión y resolverá dentro de los quince días siguientes al término del plazo de alegaciones o del que, en su caso, se fijare para las informaciones, aclaraciones o precisiones complementarias antes aludidas.

2. Si la sentencia no se produjera dentro de los cinco meses de la iniciación del conflicto, el Tribunal deberá resolver dentro de este plazo, por auto motivado, acerca del mantenimiento o levantamiento de la suspensión del acto, resolución o disposición impugnados de incompetencia por el Gobierno.

\section{Artículo 71}

La sentencia declarará la titularidad de la competencia controvertida y 
acordará, en su caso, la nulación de la disposición, resolución o actos que originaron el conflicto en cuanto estuvieren viciados de incompetencia, pudiendo disponer lo que fuera procedente respecto de las situaciones de hecho o de derecho creadas al amparo de la misma.

\section{Artículo 72}

Cuando la competencia que se estima indebidamente asumida hubiera sido atribuida por una ley o norma con rango de ley que debiera ser considerada por ello inconstitucional, el conflicto de competencias se tramitará desde su inicio o, en su caso, desde que, en defensa de la competencia ejercida, se invocara la existencia de la norma legal habilitante, en la forma prevista para el recurso de inconsticionalidad.

tema de otros motivos susceptibles de fundar la admisión o la inadmisión de la pretensión constitucional, o la de su estimación o desestimación, distintos de los alegados. La audiencia será común por plazos que no excedan de diez días y, mientras tanto, quedará en suspenso el plazo para resolver.

\section{SECCION 2.a}

De los conflictos de competencia negativos

Artículo 73

1. Cuando una persona física o jurídica se hubiese dirigido a una Autoridad administrativa del Estado o de una Comunidad Autónoma y ésta declinara su competencia en la materia de que se trate, por sostener que tal competencia corresponde a una Comunidad Autónoma, si la autoridad solicitada fuera estatal, o al Estado o a otra Comunidad Autónoma distinta, en otro caso, deberá dirigirse, una vez agotada la vía administrativa mediante la interposición de los recursos de este orden que procedieren, al órgano superior de la Administración que en la declinatoria se señala como competente, acompañando copia de la resolución recaída.

A estos efectos, se entenderán como órganos superiores los distintos Ministros del Gobierno y los órganos ejecutivos colegiados de las Comunidades Autónomas.

2. La Administración solicitada en segundo lugar deberá admitir o declinar su competencia en el plazo de un mes. Si la admitiere, procederá 
a tramitar la solicitud presentada. Si la rechazare, deberá notificarlo a la persona requirente, con indicación precisa de los preceptos en que se funda su resolución.

3. Si la Administración indicada en el apartado anterior declinare su competencia o no produjere decisión afirmativa de ésta en el plazo allí ind́icado, la persona requirente podrá acudir al Tribunal Constitucional dentro del mes siguiente a la notificación de la declinatoria o de la expiración de dicho plazo, en solicitud de que se entienda planteado un conflicto de competencia negativo.

\section{Artículo 74}

1. La solicitud de planteamiento de conflicto se hará mediante escrito en que se demuestre haber agotado el trámite previo descrito en el artículo anterior y al que se acompañarán las resoluciones recaídas durante el mismo.

2. Si el Tribunal entendiere que la negativa de las Administraciones implicadas se basa precisamente en una diferencia de interpretación de preceptos constitucionales, o de los Estatutos de Autonomía o de las Leyes orgánicas u ordinarias que delimitan los ámbitos de competencia del Estado y de las Comunidades Autónomas, declarará planteado el conflicto y dentro de los diez días siguientes al de presentación del escrito, lo comunicará así a las Administraciones implicadas, y a cualquiera otra que el propio Tribunal considerase competente, a las que remitirá copia del mismo, y al solicitante, fijando a unas y a otro el plazo común de un mes para alegar cuanto estimaren conducente a la solución del conflicto planteado.

\section{Artículo 75}

1. Dentro del mes siguiente a la conclusión del plazo señalado en el artículo anterior o, en su caso, del que sucesivamente el Tribunal hubiere concedido para responder a las peticiones de aclaración, ampliación o precisión que les hubiere dirigido, se dictará sentencia indicando cuál es la Autoridad competente.

2. Los plazos administrativos agotados se entenderán nuevamente abiertos por su duración ordinaria a partir de la publicación de la sentencia.

\section{Artículo 76}

1. Podrá igualmente entablar conflicto de competencias de carácter 
negativo el Gobierno cuando, habiendo requerido al órgano ejecutivo superior de una Comunidad Autónoma para que se inicien determinadas actuaciones a las que resultaría obligado en virtud de la competencia que a la Comunidad atribuyen sus propios Estatutos o a una Ley Orgánica de delegación o trasferencia, viese desatendido su requerimiento por declararse incompetente el órgano requerido.

2. La declaración de incompetencia se entenderá implícita por la simple inactividad del órgano ejecutivo requerido dentro del plazo que el Gobierno le hubiere fijado para el inicio de las actuaciones, que en ningún caso será inferior a un mes.

\section{Artículo 77}

1. Dentro del mes siguiente al día en que de manera expresa o tácita haya de considerarse rechazado el requerimiento a que se refiere el artículo anterior, el Gobierno podrá plantear ante el Tribunal Constitucional el conflicto negativo mediante escrito en el que habrán de indicarse los preceptos constitucionales, estatutarios o legales que a su juicio obligan a la Comunidad Autónoma a iniciar las actuaciones omitidas.

2. El Tribunal dará traslado del escrito al órgano ejecutivo superior de la Comunidad Autónoma, al que fijará un plazo de un mes para presentar las alegaciones que entienda oportunas.

3. Dentro del mes siguiente a la conclusión de tal plazo o, en su caso, del que sucesivamente hubiere fijado al Estado o a la Comunidad Autónoma para responder a las peticiones de aclaración, ampliación o precisiones que les hubiere dirigido, el Tribunal dictará sentencia en la que indicará, si fuera procedente, el plazo dentro del cual deben realizarse las actuaciones omitidas.

\section{CAPITULO III}

De los conflictos de atribuciones entre órganos constitucionales del Estado Artículo 78

1. Cuando alguno de los órganos constitucionales mencionados en el artículo $64.3 .^{\circ}$ de esta Ley considere que la actitud de cualquiera otro de estos órganos al adoptar medidas, iniciar procedimientos o rehuir deliberadamente actuaciones invade atribuciones propias conferidas en la Consti- 
tución o en las Leyes Orgánicas, se lo hará conocer así dentro del mes siguiente a la fecha en que tal actitud llegue a su conocimiento.

2. Si el órgano a que se dirige la notificación negara la existencia de tal invasión de atribuciones o, dentro del plazo de un mes a partir de la recepción de aquélla, no rectificara su actitud en el sentido que de él se requiere, el órgano que entiende invadidas sus atribuciones planteará el conflicto ante el Tribunal Constitucional mediante escrito en el que se especifiquen los preceptos que se consideran vulnerados y al que se acompañarán cuantos antecedentes y alegaciones se reputen necesarios y copias de las comunicaciones cursadas de acuerdo con lo prevenido en este artículo.

Artículo 79

Recibido el escrito, el Tribunal, dentro de los diez días siguientes, dará traslado del mismo al órgano demandado, fijándole el plazo de un mes para hacer las alegaciones que estime procedentes. Idéntica comunicación y emplazamiento se hará a todos los demás legitimados, de acuerdo con lo expuesto en el artículo anterior, para plantear este género de conflictos, los cuáles podrán comparecer en el procedimiento, en apoyo del demandante o del demandado, si entendiesen que la solución del conflicto planteado afecta de algún modo a sus propias atribuciones.

\section{Artículo 80}

1. El Tribunal podrá solicitar de las partes cuantas informaciones, aclaraciones o precisiones juzgue necesarias para su decisión y resolverá dentro del mes siguiente a la expiración del plazo de alegaciones a que se refiere el artículo anterior o del que, en su caso, se fijare para las informaciones, aclaraciones o precisiones complementarias antes aludidas, que no será superior a otros treinta días.

2. La sentencia del Tribunal determinará a que órgano corresponden las atribuciones constitucionales controvertidas y, en su caso, declarará nulos los actos ejecutados por invasión de atribuciones y resolverá, en su caso, lo que procediere sobre las situaciones jurídicas producidas al amparo de los mismos. 


\section{TITULO QUINTO}

\section{Del procedimiento previsto en el artículo 161, 2 de la Constitución}

\section{Artículo 81}

Dentro de los dos meses siguientes a la fecha de su publicación, el Gobierno podrá impugnar ante el Tribunal Constitucional las disposiciones y resoluciones emanadas de cualquier autoridad de las Comunidades Autónomas, al amparo de lo establecido en el artículo 161, 2 de la Constitución.

\section{Artículo 82}

La impugnación a que se refiere el artículo anterior, sea cual fuere el motivo de inconstitucionalidad en que se base, si se realizare invocando el presente Título, se formalizará y sustanciará por el procedimiento previsto en los artículos 67 a 72 de esta Ley.

\section{TITULO SEXTO}

\section{Del control previo de inconstitucionalidad}

\section{CAPITULO I}

Declaración sobre la constitucionalidad de los Tratados Internacionales Artículo 83

1. El Gobierno o cualquiera de ambas Cámaras podrá requerir al Tribunal Constitucional para que se pronuncie sobre la existencia o inexistencia de contradicción entre la Constitución y las estipulaciones de un Tratado Internacional cuyo texto estuviera ya definitivamente fijado, pero al que no se hubiere prestado aún el consentimiento del Estado.

2. Recibido el requerimiento, el Tribunal Constitucional emplazará al solicitante y a los restantes órganos legitimados según lo previsto en el apartado anterior, a fin de que en el término de un mes, expresen su opinión fundada sobre la cuestión. Dentro del mes siguiente al transcurso de este plazo y salvo lo dispuesto en el apartado siguiente, el Tribunal 
Constitucional emitirá su juicio, el cual, de acuerdo con lo establecido en el artículo 95 de la Constitución, tendrá carácter vinculante.

3. En cualquier momento podrá el Tribunal Constitucional solicitar de los órganos mencionados en el apartado anterior o de otras personas físicas o jurídicas u otros órganos del Estado o de las Comunidades Autónomas, cuantas declaraciones, ampliaciones o precisiones estimen necesarias, alargando el plazo de un mes antes citado en el mismo tiempo que hubiese concedido para responder a sus consultas, que no podrá exceder de treinta días.

\section{CAPITULO II}

Recurso previo sobre la constitucionalidad de los textos que hayan de ıratarse como Leyes Orgánicas

Artículo 84

1. Los órganos legitimados según lo establecido en el artículo anterior podrán igualmente interponer recurso de inconstitucionalidad, con carácter previo, frente a los proyectos normativos comprendidos en la letra a) del artículo 30 de esta Ley, una vez establecido su texto definitivo y antes de que el mismo sea sometido al siguiente trámite procedimental.

2. La interposición del recurso suspenderá automáticamente la tramitación y el transcurso de los plazos.

3. El recurso se sustanciará en la forma prevista en el Capítulo II del Título II de esta Ley, pero los Grupos Parlamentarios constituidos en ambas Cámaras de las Cortes Generales podrán comparecer para alegaciones a título propio, con independencia de que compareciese o no aquella Cámara de la que forma parte.

4. a) Cuando el pronunciamiento del Tribunal declare la inexistencia de la inconstitucionalidad alegada, seguirá su curso el correspondiente procedimiento legislativo.

b) $\mathrm{Si}$, por el contrario, declara la inconstitucionalidad del texto impugnado, deberá concretar ésta y el precepto o preceptos constitucionales infringidos. En este supuesto, la tramitación no podrá proseguir sin que tales preceptos hayan sido suprimidos o modificados por el órgano competente.

5. El pronunciamiento en el recurso previo no prejuzga la decisión del 
Tribunal en aquellos otros recursos que, eventualmente, pudieran intentarse tras la entrada en vigor con fuerza de Ley del texto impugnado en la vía previa.

\section{TITULO SEPTIMO}

\section{De las disposiciones comunes sobre procedimiento}

\section{Artículo 85}

Mientras en esta Ley no se disponga otra cosa, se aplicarán, en lo que corresponda, los preceptos de la Ley Orgánica del Poder Judicial y, en su caso, de la Ley de Enjuiciamiento Civil, en materia de comparecencia en juicio, recusación y abstención, publicidad y forma de los actos, comunicaciones y actos de auxilio jurisdiccional, días y horas hábiles, cómputo de plazos, deliberación y votación, caducidad y desistimiento, lengua oficial y policía de estrados.

\section{Artículo 86}

Los particulares legitimados para comparecer en los procesos constitucionales, como actores, o para coadyuvar a las partes principales, deberán conferir su representación a un Procurador y valerse de Abogado, que lleve su defensa. Podrán comparecer por sí mismas, para defender derechos o intereses propios, las personas que tengan título de Licenciado en Derecho, aunque no ejerzan la profesión de Procurador o de Abogado.

\section{Artículo 87}

1. Los Cuerpos y Asambleas legislativas, y las partes de los mismos, o el conjunto de Diputados o Senadores, investidos por la Constitución y esta Ley con el derecho a promover o comparecer en procesos constitucionales, actuarán en los mismos representados por el miembro o miembros que designen, o por un comisionado designado al efecto.

2. Los órganos ejecutivos, tanto del Estado como de las Comunidades Autónomas, serán representados y defendidos por sus Abogados.

Artículo 88

El Tribunal, o Sala competente, podrá, a instancia de parte o de oficio 
y en cualquier momento, y previa audiencia de los comparecidos en el proceso constitucional, disponer la acumulación de aquellos procesos con objetos conexos que justifiquen la unidad de tramitación y decisión. La audiencia se hará por plazo que no exceda de diez días.

\section{Artículo 89}

El Tribunal o Sala competente, en cualquier tiempo anterior a la decisión, podrá someter a los comparecidos en el proceso constitucional, el tema de otros motivos susceptibles

\section{Artículo 90}

1. La iniciación de un proceso constitucional deberá hacerse por escrito fundado en el que se fijará con precisión y claridad lo que se pida.

2. Los escritos improcedentes o manifiestamente infundados pueden ser rechazados por decisión del Tribunal, la Sala o la Sección, en su caso. Podrá el Tribunal, la Sala o la Sección, advertir previamente al peticionario de los motivos que pudieran justificar la inadmisión, con objeto de que en el plazo que no excediera de diez días, subsane, si procediere, los defectos advertidos.

\section{Artículo 91}

La decisión del proceso constitucional se producirá en forma de sentencia. Sin embargo, las decisiones de admisión inicial, sobreseimiento, desistimiento y caudcidad adoptarán la forma de auto. Las otras resoluciones adoptarán la forma de providencia, motivadas o no, según la índole de su contenido.

\section{Artículo 92}

1. Todos los poderes públicos están obligados al cumplimiento de lo que el Tribunal Constitucional disponga.

2. Los Juzgados y Tribunales prestarán al Tribunal Constitucional el auxilio jurisdiccional que éste solicite. 


\section{Artículo 93}

1. El Tribunal Constitucional, o la Sala competente, podrá recabar de las Cámaras, o de las Asambleas legislativas, del Gobierno o de los Organos Ejecutivos, o de la Administración, la entrega o remisión del expediente y los informes y documentos precisos, referentes a la disposición o acto por razón del cual se sigue el proceso constitucional.

Cuando se adopte esta decisión, el Tribunal dispondrá un trámite para que el expediente, la información o la documentación, pueda ser conocido por las partes del proceso constitucional, a los efectos, en su caso, de hacer alegaciones.

2. El Tribunal dispondrá las medidas necesarias para preservar el secreto que pudiera afectar a determinadas actuaciones.

\section{Artículo 94}

El Tribunal, a instancia de parte o de oficio, acordará la práctica de pruebas cuando fuere necesario para la constatación de hechos relevantes en la decisión y resolver libremente sobre el tiempo y forma de realización de aquella.

Cuando un testigo sólo pueda comparecer o ser interrogado con autorización superior, la Autoridad a la que corresponde otorgar la misma expondrá, en su caso, al Tribunal las razones que, a su juicio, justifican la denegación de la autorización. El Tribunal, oído este informe, resuelve con libertad de criterio.

\section{Artículo 95}

1. El Tribunal, en pleno, en Sala o en Sección, resuelve las cuestiones sometidas a su competencia en deliberación secreta y por mayoría de votos, siendo de calidad el del Presidente.

2. El Presidente, y los Magistrados del Tribunal, podrán reflejar en un voto particular su opinión disidente defendida en la deliberación, tanto por lo que se refiere a la decisión como a su fundamentación. El voto particular se incorporará a la resolución o dictamen y cuando se trate de sentencias, se publicarán con éstas en el Boletín Oficial del Estado.

\section{Artículo 96}

El Tribunal podrá suspender el procedimiento que se sigue ante el mismo hasta la resolución de un proceso penal pendiente ante un Juzgado o Tribunal de este orden. 
Artículo 97

El Tribunal podrá disponer en la Sentencia, o en la resolución, o en actos posteriores, quién ha de ejecutarla y, en su caso, resolver las incidencias de la ejecución.

\section{Artículo 98}

Contra las Sentencias del Tribunal Constitucional no cabe recurso alguno salvo el de aclaración, que podrá formularse en el plazo de dos días.

Contra las providencias y los autos que dicte el Tribunal Constitucional, sólo procederá, en su caso, el recurso de súplica que no tendrá efecto suspensivo. El recurso podrá interponerse en el plazo de tres días y se resolverá, previa audiencia común de las partes por igual tiempo, en los dos siguientes.

\section{Artículo 99}

E1 Tribunal, a instancia de parte o de oficio, podrá subsanar y convalidar, en cualquier tiempo, los defectos que hubieran podido producirse en el procedimiento.

Artículo 100

1. El procedimiento del Tribunal Constitucional es gratuito.

2. Si la petición deducida en el proceso resulta infundada, deberá el accionante satisfacer, a la parte o partes perjudicadas, las expensas necesarias, con inclusión de los gastos de defensa, según la tasación que apruebe libremente el Tribunal.

3. El Tribunal podrá imponer a quien formulare recursos de inconstitucionalidad o de amparo, con temeridad o abuso de derecho una sanción pecuniaria de 5.000 a 100.000 pesetas.

Igualmente, podrá imponer multas coercitivas de 5.000 a 50.000 pesetas a cualquier persona, investida o no de poder público, que incumpla los requerimientos del Tribunal dentro de los plazos señalados y reiterar estas multas hasta el total cumplimiento de lo interesado, sin perjuicio de cualquier otra responsabilidad a que hubiere lugar.

Los límites de la cuantía de estas sanciones o multas podrán ser revisados, en todo momento, a propuesta del Tribunal, mediante Ley ordinaria. 


\section{TITULO OCTAVO}

\section{Del personal al servicio del Tribunal Constitucional}

Artículo 101

Son funcionarios al servicio del Tribunal Constitucional:

- El Secretario General.

- Los Letrados Constitucionales.

- Los Secretarios de Justicia.

- Los Oficiales, los Auxiliares y los Agentes.

Este personal se rige por lo establecido en esta Ley y en el Reglamento que en su desarrollo se dicte $y$, con carácter supletorio, en lo que sea aplicable, por la legislación vigente para el personal al servicio de la Administración de Justicia.

Artículo 102

Sin perjuicio de las facultades que respecto del personal al servicio del Tribunal Constitucional tiene el Presidente y el Secretario General y, en su caso, los otros órganos del Tribunal, el Ministro de Justicia es el competente en lo referente al nombramiento y cese de este personal y contenido de la relación funcionarial.

\section{Artículo 103}

El Tribunal Constitucional estará asistido por un Cuerpo de Letrados Constitucionales que se integrará, por terceras partes, en virtud de concurso, entre miembros de la carrera judicial o fiscal, Letrados de las Cortes y Letrados del Consejo de Estado, con un mínimo de cinco años de servicio activo en sus respectivos Cuerpos.

Los nombrados quedarán en su carrera de origen en situación de supernumerarios por todo el tiempo en que presten sus servicios en el Tribunal Constitucional.

El concurso tenderá a elegir a aquellos que, además de los conocimientos jurídicos generales, posean una especialización jurídica pública. La selección se realizará por una Comisión nombrada por el Presidente del Tribunal y constituida, bajo su presidencia, por los Vocales siguientes:

a) Tres Magistrados del Tribunal Constitucional.

b) Un Catedrático de Universidad.

c) Un Magistrado del Tribunal Supremo o su Fiscal General. 
d) Un Letrado de las Cortes.

e) Un Letrado del Consejo de Estado.

f) El Secretario del Tribunal Constitucional y, en su defecto, el Magistrado del Tribunal más moderno o de menor edad, que actuará como Secretario de la Comisión.

\section{Artículo 104}

El Tribunal Constitucional tendrá un Secretario General nombrado por el Presidente entre los Letrados Constitucionales, que desempeñará la Secretaría General del Tribunal y ostentará la jefatura de los Letrados, sin perjuicio de las facultades que corresponden al Presidente, al Tribunal y a las Salas.

\section{Artículo 105}

1. Corresponde al Secretario General organizar y distribuir los servicios jurídicos, administrativos y subalternos del Tribunal, dando conocimiento al Presidente; dirigir y coordinar el trabajo de los Letrados Constitucionales; proponer al Presidente los turnos de vacaciones del personal del Tribunal, ejercer la jefatura de este personal y dirigir la Secretaría General del Tribunal.

2. Corresponde, igualmente, a la Secretaría General la recopilación, clasificación y publicación de la doctrina constitucional del Tribunal.

\section{Artículo 106}

El Tribunal y las Salas tendrán el número de Secretarios de Justicia que se determinen. Los Secretarios de Justicia procederán del Cuerpo de Secretarios de la Administración de Justicia y las vacantes se cubrirán por concurso de méritos entre quienes pudieran ocupar plaza en el Tribunal Supremo.

\section{Artículo 107}

Los Secretarios de Justicia ejercerán en el Tribunal o en las Salas la fe pública judicial y desempeñarán, respecto del Tribunal o Sala a la que estén adscritos, las funciones que la legislación orgánica y procesal de los Juzgados y Tribunales atribuye a los Secretarios.

\section{Artículo 108}

Se adscribirán al Tribunal Constitucional, Oficiales, Auxiliares, Agen- 
tes y demás personal, en la medida necesaria para atender el servicio.

El Reglamento fijará las condiciones necesarias para el acceso a estos cargos.

Artículo 109

La dotación económica del Secretario General, de los Letrados Constitucionales, de los Secretarios y de los Oficiales, Auxiliares, Agentes y demás personal, se fijará en los Presupuestos Generales del Estado.

Los cargos relacionados en este artículo son incompatibles con cualquier otra función, destino o cargo, así como con el ejercicio profesional y con la intervención en actividades industriales, mercantiles o profesionales, incluso las consultivas y las de asesoramiento. No obstante, podrán ejercer aquellas funciones docentes o de investigación que, a juicio del Tribunal, no resulten incompatibles con el mejor servicio de éste.

\section{DISPOSICIONES TRANSITORIAS}

Primera

1. Dentro de los tres meses siguientès a la fecha de la entrada en vigor de la presente Ley, el Congreso de los Diputados, el Senado, el Gobierno y el Consejo General del Poder Judicial, elevarán a Su Majestad las propuestas de designación de los Magistrados del Tribunal Constitucional. Este plazo se interrumpirá para las Cámaras por el tiempo correspondiente a los períodos intersesiones.

2. El Tribunal se constituirá dentro de los quince días siguientes a la fecha de publicación de los últimos nombramientos, si todas las propuestas se elevasen dentro del mismo período de sesiones. En otro caso, se constituirá en los quince días siguientes, al término del período de sesiones dentro del que se hubiesen efectuado los ocho primeros nombramientos.

Segunda

1. Los plazos previstos en esta Ley para interponer los recursos de inconstitucionalidad o de amparo o promover un conflicto constitucional comenzarán a contarse desde el día de la entrada en vigor de la presente Ley cuando las leyes, actos, disposiciones o resoluciones que originan el recurso o conflicto fueran anteriores a ella y no hubieran agotado sus efectos. 
2. En tanto no sean desarrolladas las previsiones del artículo 53 de la Constitución para configurar el procedimiento judicial de protección de los derechos y libertades fundamentales se entendrá que la vía judicial previa a la interposición del recurso de amparo es la configurada en la sección segunda de la Ley 62/78 de 26 de diciembre «Sobre protección jurisdiccional de los Derechos Fundamentales".

\section{Tercera}

1. Los sorteos a que se refiere la disposición transitoria novena de la Constitución se efectuarán dentro del cuarto mes anterior a la fecha en que se cumplen, respectivamente, los tres o los seis años de aquella otra en que se produjo la inicial designación de los jueces del Tribunal Constitucional.

2. No será aplicable la limitación establecida en el artículo $17,2 .^{\circ}$ de esta Ley a los Magistrados del Tribunal los que cesaren en sus cargos, en virtud de lo establecido en la Disposición Transitoria novena de la Constitución, a los tres años de su designaçión.

\section{Cuarta}

El Gobierno habilitará los créditos necesarios para el funcionamiento del Tribunal Constitucional hasta que éste disponga de presupuesto propio.

\section{DISPOSICIONES ADICIONALES}

\section{Primera}

1. El Tribunal Constitucional dispondrá inicialmente de dieciséis Letrados Constitucionales y de tres Secretarios de justicia.

2. El Tribunal, una vez instituido, establecerá la plantilla de su personal, que sólo podrá ser modificada a travês de la Ley de Presupuestos.

\section{Segunda}

1. El Tribunal elaborará su presupuesto, que figurará como una Sección dentro de los Presupuestos Generales del Estado. 
2. El Secretario General, asistido de personal técnico, asumirá la preparación, ejecución y liquidación de presupuesto.

ELEVESE AL CONSEJO DE MINISTROS

Madrid, 18 de abril de 1979

EL MINISTRO DE LA PRESIDENCIA 